\title{
Portfolio Optimization Using a Combined Model of Fuzzy Network Analytic Process: An Approach Based on Similarity and Genetic Algorithm
}

\author{
Mohammad Bahrani Jahromi ${ }^{1}$, Sahar Kamalzadeh ${ }^{1} \&$ Hedayat Tajik ${ }^{2}$ \\ ${ }^{1}$ School of Management, Tehran University, Tehran, Iran \\ ${ }^{2}$ School of Entrepreneurship, Tehran University, Tehran, Iran \\ Correspondence: Sahar Kamalzadeh, School of Management, Tehran University, Tehran, Iran. Tel: \\ 98-912-460-6756. E-mail: Saharkamalzadeh2009@gmail.com \\ Received: April 13, 2015 \\ Accepted: May 25, 2015 \\ Online Published: July 25, 2015 \\ doi:10.5539/ijef.v7n8p88 \\ URL: http://dx.doi.org/10.5539/ijef.v7n8p88
}

\begin{abstract}
Portfolio management has always been an issue of high importance in financial markets. This paper is an attempt to introduce a new technique of portfolio selection. After presenting a review of literature on factors influencing portfolio selection, the importance of each factor is determined in regards to experts' opinions and a weight is assigned to each factor using fuzzy network analytic process technique. Consequently, using an approach based on TOPSIS and similarity, selected stocks were ranked. After depicting efficient frontiers of the top ranks obtained from both approaches, using genetic algorithm, Sharpe ratio was used in order to examine model's performance.
\end{abstract}

Keywords: portfolio selection, fuzzy network analytic process, similarity-based approach, topsis approach, genetic algorithm

\section{Introduction}

A great number of economists refer to capitalization as the most important factor of economic development (Gholizadeh, 2004). Economies all over the world, owe their development to capital markets to a great extent. Security markets provide all the housholds with the opportunity to unite their small savings to finance a company; thus paving the way to the overall development of the economy by creating synergy.

Existence of a prosperous and active capital market in a country is considered as a sign of development all over the world. Most of investments are carried out through financial markets in developed countries. Active participation of society members in Exchanges would guarantee capital market's survivor and sustainable growth of that country. The basic issue with which every investor faces is deciding about appropriate securities of investment and to create an optimal portfolio.

Decision making considering several criteria each of which has a specific importance can be done only by multi criteria decision models. Several criteria proportionate to ranking model are used in these models (Saremi, Safari, Fathi, \& Hoseini, 2006). In this study, we are going to use these criteria in order to select an optimal portfolio.

\section{Research Literature}

Examining research background about employed decision approaches for portfolio selection, it can be said that: In a research in 2003, Mezziani from Monte Cleare University tried to assess international capital flow limitations and obstacles using AHP model. He uses a hierarchy analytic to prove how an optimal capital security portfolio can be established so that the capital flows have the least effect on it (Meziani, 2003). Tiryaki and Ahlatcioglu (2009) were combining Fuzzy MCDM and portfolio selection issue and trying to present a more effective model. They ranked and assigned weights to securities using Revised Constrained Fuzzy AHP and security selection problem (Tiryaki \& Ahlatcioglu, 2009). Kiris and Ustun (2010) evaluated 9 shares of stock from ISE by fuzzy MCDM approach. Performance of selected securities is measured against each criterion with linguistic expressions. First, they used AHP and assigned weights to each security regarding investors' preferences, and then based on its performance determined each security's proportion in established portfolio (Kiris \& Ustun, 2010). Research done by Lee et al. (2008) is an example of using ANP technique for selecting 
optimal portfolio. They sought effective factors and suitable weights to select stock portfolios. They selected the criteria based on Gordon model (Lee, Tzeng, Guan, Chien, \& Huang, 2008). Lee et al. (2011) claimed that different investment methodologies such as fundamental and technical analysis, institutional investor analysis, determine important factors of stocks price behavior but they can't fully explain much of relevant key factors. They analyzed the relationships among various factors using DEMATEL technique and ANP. They argue that profitability growth and trade volume, among others, are respectively the most effective factors of investment decision (Lee, Haung, Chang, \& Cheng, 2011). Banakar introduces 15 financial criteria in 4 clusters nominated: profitability, growth, market and risk. He first assigned weights to the criteria using ANP. Then, they ranked them by TOPSIS and, finally, optimized them using Memtic algorithm (Amiri, Shariatpanahi, \& Banakar, 2010).

\section{Methodology}

Factors influencing stock portfolio selection have been chosen after portfolio selection and optimization literature, financial books and comments of capital market experts were reviewed. Those criteria, among extracted ones, which had fundamental and quantitative properties and could be obtained from financial statements and Exchange information, were selected. Then, portfolio was selected and optimized using operational research methods. In this way, we assigned a weight to each criteria using fuzzy analytic network process and ranked them by a similarity-based approach. In order to make sure of proposed model's performance, securities were ranked using TOPSIS approach once more and efficient frontiers of top ranks were depicted and Sharpe performance measure was calculated.

\section{Determinants of Stock Selection for Evaluation}

According to literature review and experts' opinions, the specified criteria were categorized in four main clusters including performance, growth, market and risk clusters. Considering that profitability is pure result of employing decisions and policies and based on the fact that profitability ratios are achieved through liquidity and assets management effects, we abandoned liquidity and efficiency ratios and focused on profitability cluster alone. As leverage ratios influence firm's risk, those leverage ratios were eliminated and risk cluster was considered instead. Therefore, based on mentioned concerns, assumed criteria are as follows:

\section{A) Profitability cluster criteria}

Return on assets: this ratio measures the return per unit of investment in assets (Ross, Westerfield, Jordan, \& Roberts, 2002).

Return on equity: net profit each unit of equity yields and it is known as return gained by investors (Ross, Westerfield, Jordan, \& Roberts, 2002).

Operating profit margin: net profit minus dividend of preferred stock divided by number of common shares outstanding

Net profit margin: Net profit of a firm generates by each unit of revenue (Edirisinghe \& Zhang, 2008).

Earnings per share: Net income minus preferred dividends divided by the number of ordinary shares (Edirisinghe \& Zhang, 2008).

B) Growth cluster criteria

Revenues growth rate: Degree of changes in firm's gains in a given period of time (Brickley, 1983).

Net profit growth rate: Degree of changes in firm's net profit in a given period of time (Edirisinghe \& Zhang, 2008).

Sustainable growth rate: it is the maximum rate of growth which can be achieved without an increase in leverage ratio and capital raise. It is calculated in this way (Higgins, 1977):

$$
g=R O E(1-\text { dividend payout ratio })
$$

EPS growth rate: Degree of change in firm's earnings per share in a given period of time.

C) Risk cluster criteria

Business risk: it is the uncertainty of firms' revenues due to changing conditions of industry. Business risk is calculated as standard deviation of operating revenue is divided by its mean (Reilly \& Brown, 2003).

Financial risk: it is the uncertainty and risk of return on equity due to firm's usage of other capital instruments such as bond liability and debts and it is added to firm's business risk (Reilly \& Brown, 2003).

Market risk: variability in returns of overall securities which has a direct relationship to market of general economy overall upheavals is called systematic risk (Raei \& Pooyan Far, 2004). 


\section{D) Market cluster criteria}

Market to book value ratio: Fama and French (1992) showed that this ratio can explain cross sectional variation of stock return (Fama \& French, 1992).

Price to Earnings ratio: this ratio shows that, given a specified level of current income, how much investors are willing to pay for each share of stock (Brigham \& Ehrhardt, n.d.).

Dividend ratio: any percent of earnings per share divided among investors as cash dividend.

\section{Statistical Population}

Statistical population of this study is defined in two levels. At the first level, dealing with selection criteria, inference of significance weights and interrelationship between factors effecting portfolio selection, as well as experts and investment decision makers comprising a group of 5 people are used. The second level consists of firms of Tehran Stock Exchange. Industries were identified based upon reviews of documents filed with Tehran Securities Exchange Company. A 3-year time horizon from 2006-2009 was used for the study and companies which entered or exited the market through this period were excluded. Construction, automobile, medicine, cement, petrochemicals, base metals and metal ore mining were identified as 7 industries constitute more than 80 percent of market's value, and no firms were selected from other industries because of their small market value and trade volume. We didn't study bankers, financial institutions and investment firms industries because their financial statements are of different types. Finally, we collected 153 firms. We eliminated firms, trading days of which were less than 9 months a year and 10 days a month, so that we could evaluate liquidity measure and draw efficient frontier for portfolio. Therefore, remaining firms summed 80.

\subsection{Information Collection Methods and Instruments}

A questionnaire the potential correlation among factors effecting portfolio selection was used to find and measure possible correlation among criteria, and a questionnaire degree of relative importance of factors effecting portfolio selection was used to specify the importance of factors effecting portfolio selection. Financial ratios were calculated through examination of financial statements of listed firms in TSE and by means of Rahavard Novin software. In order to find weights of criteria by fuzzy analytic network process, Super Decision software was used, and Excel software was applied to rank stocks by similarity-based and TOPSIS approaches.

In addition, MATLAB software has been used to optimize selected portfolio based on genetic algorithm.

\section{Analytic Network Process (ANP)}

Saati (1996) extended AHP to ANP to provide a more comprehensive research framework for evaluating various decisions and offsetting its shortcomings. ANP is a new theory which extends analytic hierarchy process to address dependency of feedback and uses super matrix to do so. Although both methods determine priorities on the basis of paired comparisons, they have some differences; first due to the fact that network analysis considers intracluster (internal dependency) and intercluster (external dependency) correlation, AHP is a special form of network analysis (Saaty, 1996).

Since financial ratios are principal criteria used to select securities and most of these ratios are interrelated (interdependent), it is impossible to use AHP technique. Therefore, we used ANP technique in this study so that the experts could provide us with the level of importance of each criterion and we could measure these levels of exploring behaviors of investors.

\section{Phases of ANP}

An analytic network process has five phases. At first, structure and model of the problem are formulated. Secondly, paired comparisons are constructed, special values and special vectors are calculated. Level (degree, intensity) of importance is measured based upon a score scale (1-9) and geometric average applied to integrate paired comparisons. Now, local priority vector is defined by following relationship:

$$
\lambda_{\max } \cdot W=A . W
$$

Where $\mathrm{A}$ is the paired comparisons matrix, $\mathrm{W}$ is the special vector, $\lambda_{\max }$ is the largest vector among values of $\mathrm{A}$.

Third, consistency test was done. Results of the paired comparisons matrix are analyzed through consistency rate (CR) for consistency; this rate is obtained through consistency index (CI) and random index (RI). If $\mathrm{CR} \leq 0.1$, this matrix is consistent and inconsistent results are corrected immediately. Fourthly, super matrix is established. Super matrix concept resembles to Markov sequence process. Super matrix can limit the coefficients to calculate all priorities, thereby, cumulative effect of each element on the other elements of the interaction (Saaty, 1996).

Fifth, the best alternative is selected. If the super matrix created through previous phases covers all over the 
network, weights of priorities can be found in alternatives column in a normalized super matrix. Final preferences are acquired through following solution:

$$
\lim _{x \rightarrow \infty} W_{n}^{2 K+1}
$$

$\mathrm{W}_{\mathrm{n}}$ is super matrix of the study, $\mathrm{K}$ is an arbitrary large number, and raising the super matrix to power, the super matrix is converged, and therefore, its weights are stabilized. Finally, the alternative with the highest priority is considered as the first top alternative.

\section{Fuzzy Set and Fuzzy Numbers}

In 1965, Zadeh introduced fuzzy sets theory to solve problems involving lack of accurate (precise) criteria (Zadeh, 1995). A triangular fuzzy number is shown in Figure 1. Such a number is simply specified as $(1 / \mathrm{m}, \mathrm{m} / \mathrm{u})$ and $(\mathrm{l}, \mathrm{m}, \mathrm{u})$. Parameters $1, \mathrm{~m}$ and $\mathrm{u}$ represent the smallest, the most probable and the largest expected value, respectively, that describe a fuzzy event. $1, \mathrm{~m}$ and $\mathrm{u}$ are real numbers where $\mathrm{l} \leq \mathrm{m} \leq \mathrm{u}$. if $\mathrm{l}=\mathrm{m}=\mathrm{u}$, then $\mathrm{M}$ will be a non-fuzzy number.

Each triangular fuzzy number has a linear representation on the left and the right and its membership function can be defined as follows:

$$
\mu(x / M)= \begin{cases}0, & x \prec 1 \\ (x-1) /(m-1), & l \leq x \leq m \\ (u-x) /(u-m), & m \leq x \leq u \\ 0, & x \succ u\end{cases}
$$

Each fuzzy number can always be given by its corresponding left and right representation of each degree of membership:

$$
\begin{aligned}
& M=\left(M^{l(y)}, M^{r(y)}\right)=(l+(m-1) y, u+(m-u) y), \\
& y \in[0,1]
\end{aligned}
$$

Where, $1(\mathrm{y})$ and $\mathrm{r}(\mathrm{y})$ are representatives of left and right sides of the fuzzy number, respectively. Consider the following figure.

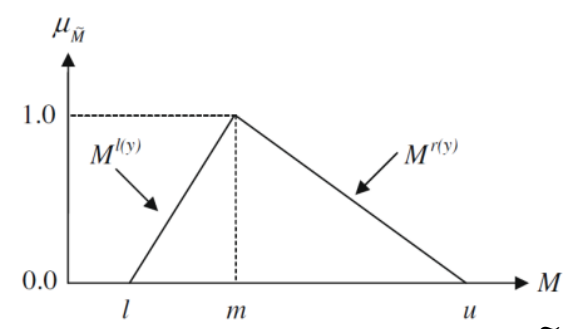

Figure 1. A triangular fuzzy number, $\widetilde{M}$

Many ranking methods have been established in literature for fuzzy numbers. This methods result in different rankings and most of these methods need complex mathematical calculations. Therefore, graphic manipulation will be tedious. See also Kahraman et al. (2002) for algebraic operations (Kahraman, Ruan, \& Tolga, 2002).

It is supposed that decision makers use linguistic measures to assign weights:

Table 1. Lingual criteria used to measure intensity of importance (Lee, Chen, \& Chang, 2008)

\begin{tabular}{lcc}
\hline Linguistic scale & Triangular fuzzy scale & Triangular fuzzy reciprocal scale \\
\hline Strongly important & $(9,9,9)$ & $1 / 9,1 / 9,1 / 9))$ \\
Intermediate value & $7,8,9))$ & $1 / 9,1 / 8,1 / 7))$ \\
Moderately important & $6,7,8))$ & $1 / 8,1 / 7,1 / 6))$ \\
\hline
\end{tabular}


Table 2. Lingual criteria used to measure intensity of importance (Lee, Chen, \& Chang, 2008)

\begin{tabular}{ccc}
\hline Linguistic scale & Triangular fuzzy scale & Triangular fuzzy reciprocal scale \\
\hline Intermediate value & $5,6,7))$ & $1 / 7,1 / 6,1 / 5))$ \\
Weakly important & $4,5,6)$ ) & $1 / 6,1 / 5,1 / 4)$ ) \\
Intermediate value & $3,4,5)$ ) & $1 / 5,1 / 4,1 / 3)$ ) \\
\hline
\end{tabular}

Table 3. Lingual criteria used to measure intensity of importance (Lee, Chen, \& Chang, 2008)

\begin{tabular}{ccc}
\hline Linguistic scale & Triangular fuzzy scale & Triangular fuzzy reciprocal scale \\
\hline Equally important & $2,3,4))$ & $1 / 4,1 / 3,1 / 2))$ \\
Intermediate value & $1,2,3))$ & $1 / 3,1 / 2,1 / 1))$ \\
Just equal & $1,1,1))$ & $1,1,1))$ \\
\hline
\end{tabular}

\section{Fuzzy Analytic Network Process}

We use extent analysis method introduced by Chang $(1992,1996)$ in this study, because its phases are easier than other fuzzy analytic hierarchy process approaches. Chang extent analysis approach phases are: determining $X=\left\{x_{1}, x_{2}, \ldots, x_{n}\right\}$ as object set and $U=\left\{u_{1}, u_{2}, \ldots, u_{m}\right\}$ as goal set. According to Chang extent analysis, each object is taken and extent analysis for each goal, $\mathrm{g}_{\mathrm{i}}$, is performed, respectively. Therefore, m extent analysis values for each object can be obtained, with the following signs:

$$
M_{g i}^{1}, M_{g i}^{2}, \ldots, M_{g i}^{m}, i=1,2, \ldots, n
$$

$M_{g i}^{j}(j=1,2, \ldots, m)$ Where, all values are triangular fuzzy numbers. Chang extent analysis phases include:

Step 1: The value of fuzzy synthetic extent with respect to the $i_{\text {th }}$ object is defined as

$$
S_{i}=\sum_{j=1}^{m} M_{g i}^{j} \otimes\left[\sum_{i=1}^{n} \sum_{j=1}^{m} M_{g i}^{j}\right]^{-1}
$$

In order to calculate $\sum_{j=1}^{m} M_{g i}^{j}$, an additional fuzzy operation of $\mathrm{m}$ extent analysis values for a particular matrix is applied:

$$
\sum_{j=1}^{m} M_{g i}^{j}=\left(\sum_{j=1}^{m} l_{j}, \sum_{j=1}^{m} m_{j}, \sum_{j=1}^{m} u_{j}\right)
$$

To calculate $\left[\sum_{i=1}^{n} \sum_{j=1}^{m} M_{g i}^{j}\right]^{-1}$, do an additional fuzzy operation of $M_{g i}^{j}(j=1,2, \ldots, m)$ values such that:

$$
\sum_{i=1}^{n} \sum_{i=1}^{m} M_{g i}^{j}=\left(\sum_{i=1}^{n} l_{i}, \sum_{i=1}^{n} m_{i}, \sum_{i=1}^{n} u_{i}\right)
$$

And then calculate the inverse of the vector in equation 8 such that:

$$
\left[\sum_{i=1}^{n} \sum_{j=1}^{m} M_{g i}^{j}\right]^{-1}=\left(\frac{1}{\sum_{i=1}^{n} u_{i}}, \frac{1}{\sum_{i=1}^{n} m_{i}}, \frac{1}{\sum_{i=1}^{n} l_{i}}\right)
$$

Step 2: the degree of possibility of $M_{2} \geq M_{1}$ is defined as

$$
V\left(M_{2} \geq M_{1}\right)=S U P\left[\min \left(\mu_{M_{1}}(x), \min \left(\mu_{M_{2}}(y)\right)\right]\right.
$$

And it can be considered as the equivalent of: 


$$
\begin{aligned}
& V\left(M_{2} \geq M_{1}\right)=\operatorname{hgt}\left(M_{1} \cap M_{2}\right)=\mu_{M_{2}}(d)= \\
& = \begin{cases}1, & \text { if } m_{2} \geq m_{1} \\
0, & \text { if } l_{2} \geq u_{2} \\
\frac{l_{1}-u_{2}}{\left(m_{2}-u_{2}\right)-\left(m_{1}-l_{1}\right)}, & \text { otehrwise }\end{cases}
\end{aligned}
$$

We need values of both to calculate $M_{1}$ and $M_{2}$.

D is the latitude of the highest intersect point between $\mu_{M_{1}}$ and $\mu_{M_{2}}$ (see Figure 2). We need the values of $V\left(M_{1} \geq M_{2}\right)$ and $V\left(M_{2} \geq M_{1}\right)$ in order to compare $M_{1}$ and $M_{2}$.

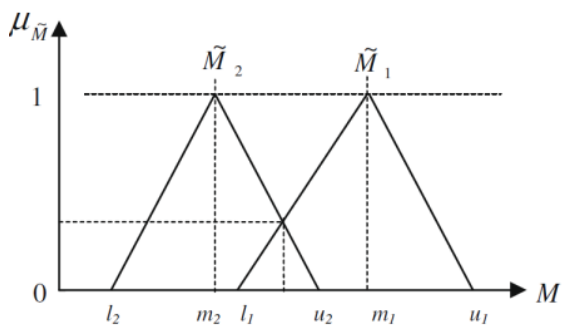

Figure 2. The intersection between $\mathrm{M}_{1}$ and $\mathrm{M}_{2}$

Step 3. How much a fuzzy number is larger than k other fuzzy numbers, can be defined through this relationship:

$$
\begin{aligned}
& V\left(M \geq M_{1}, M_{2}, \ldots, M_{k}\right)=V\left[\left(M \geq M_{1}\right)\right. \\
& \text { and } \left.\left(M \geq M_{2}\right) \text { and } \ldots \text { and }\left(M \geq M_{k}\right)\right] \\
& =\min V\left(M \geq M_{i}\right), i=1,2, \ldots, k
\end{aligned}
$$

Assume that:

$$
d^{\prime}\left(A_{i}\right)=\min V\left(S_{i} \geq S_{k}\right), \quad k=1,2, \ldots, n ; \quad k \neq i
$$

So weighted vector follows:

$$
W=\left(d^{\prime}\left(A_{1}\right), d^{\prime}\left(A_{2}\right), \ldots, d^{\prime}\left(A_{n}\right)\right)^{T}
$$

Where, $A_{i}(i=1,2, \ldots, n)$ are n elements?

Step 4: normalized weighted vector is as below after normalizations:

$$
W^{\prime}=\left(d\left(A_{1}\right), d\left(A_{2}\right), \ldots, d\left(A_{n}\right)\right)^{T}
$$

Where W is a non-fuzzy number (Chang, 1992; Chang, 1996).

\section{How Criteria of Stock Selection Affect Each Other}

We used prior researches and financial ratios analysis to examine the relationships and influences among criteria. For example, as net profit margin and assets turnover increase, return on assets enhances, too. It can be shown, through de Ponte system analysis, that the higher net profit margin, total assets turnover, and debt ratio, the higher return on equity. As return of equity and dividend payout ratios rise, firm's potential growth rate increases. According to Gordon model, dividend payout ratio and potential growth rate both influence price to earning ratio. Also, market risk lead expected rate of return to rise, and again, it affects price to earnings ratio. Various risks certainly affect market ratios. In addition, firm's financial risk relates to its business risk. If business risk of an institution is low, investors accept higher financial risk. Lee et al., state when a firm forecasts more and stable cash flows for future, it pays more dividend, so firm's revenue is among parameters which affect this ratio. Financial leverage is another parameter that affects dividend payout policy, that is, larger financial leverage leads more dividend payments to shareholders. Firms whose return on equity ratio is relatively high sell their shares much higher than their book value (Edirisinghe \& Zhang, 2008; Amiri, Shariatpanahi, \& Banakar, 2010; Reilly \& Brown, 2003; Lee, Chen, \& Chang, 2008). 


\section{Prioritizing Criteria Using Fuzzy Analytic Network Process}

After criteria for selecting stocks were determined, analytic network process has been employed to do paired comparisons, examine dependencies among criteria, depict the network and, finally, decide weights of importance for each criterion. Fig.3 shows the network and relationships of the criteria.

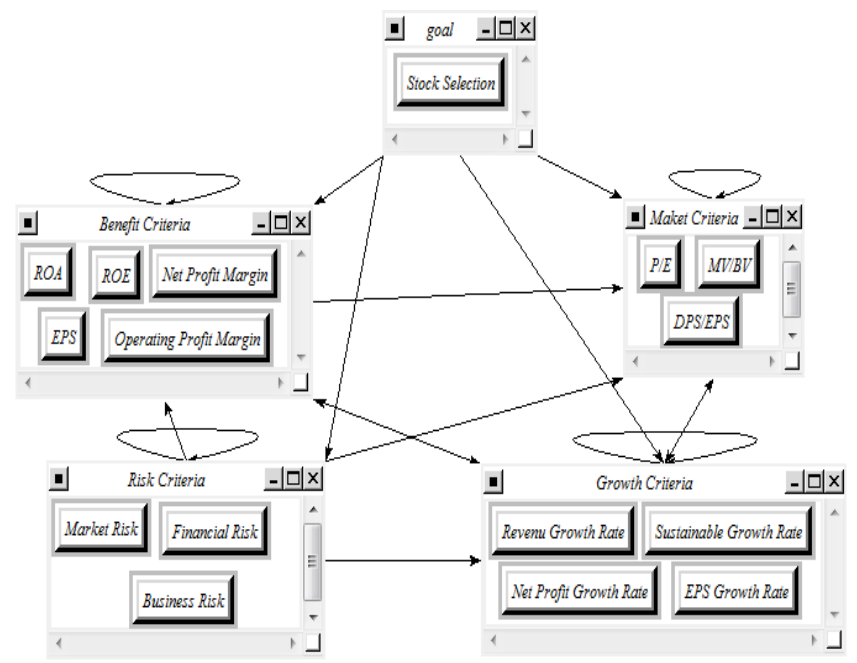

Figure 3. Network of relationships between clusters and criterias (super decisions software)

When paired comparisons matrix and weight of each criterion were culated, they would be placed in super matrix. Therefore, unweighted super matrix, cluster matrix and weighted matrix should be established. Placing each special vector (weights) extracted from paired comparisons matrix of criteria's level of importance in its appropriate position, unweighted super matrix will be established. Clusters themselves should be compared so that the importance of their relationships is specified. The matrix resulting from multiplication of cluster matrix elements by correspondence blocks of unweighted matrix is called weighted matrix. We should raise weighted super matrix to higher powers in order for each row of weighted matrix will converge, so that ultimate weight will be calculated and sustainable limit will be achieved. Figure 4 shows normalized weights in each cluster and their ultimate weights.

\begin{tabular}{|c|c|c|c|}
\hline Name & \multicolumn{3}{|c|}{$\sqrt{\text { Normalized by Cluster } / \text { Limiting }}$} \\
\hline EPS & Г & 0.21817 & 0.088485 \\
\hline Operating Profit Margine & Г & 0.28366 & 0.115045 \\
\hline ROA & Г & 0.13001 & 0.052729 \\
\hline ROE & Г & 0.16363 & 0.066364 \\
\hline Net Profit Margin & Г & 0.20454 & 0.082955 \\
\hline Stock Selection & Г & 0.00000 & 0.000000 \\
\hline EPS Growth Rate & Г & 0.16916 & 0.076168 \\
\hline Growth Rate & Г & 0.33085 & 0.148974 \\
\hline Net Profit Growth Rate & $\Gamma$ & 0.26368 & 0.118730 \\
\hline Revenue Growth Rate & $\Gamma$ & 0.23632 & 0.106411 \\
\hline DPS/EPS & Г & 0.17898 & 0.016169 \\
\hline MV/BV & $\Gamma$ & 0.20505 & 0.018524 \\
\hline P/E & $\Gamma$ & 0.61597 & 0.055647 \\
\hline Bussines Risk & Г & 0.36923 & 0.019864 \\
\hline Financial Risk & Г & 0.57221 & 0.030784 \\
\hline Market Risk & Г & 0.05855 & 0.003150 \\
\hline
\end{tabular}

Figure 4. Final wights of criterias (super decision's outcome)

\section{Similarity-Based Approach to Ranking Multicriteria Analysis}

This technique, introduced by Hepu deng, would provide a similarity-based approach to rank alternatives for solving multicriteria discrete problems. The approach uses ideal solution concept efficiently, that is, better alternative must have the highest similarity to positive ideal solution and the least similarity to negative ideal solution. Performance index of each alternative against each criterion is determined based on the concept of 
degree of similarity between each alternative and ideal solution using its gradient and magnitude.

Suppose that $A_{i}$ and $A_{j}$ are two alternatives in a multicriteria analysis problem; these two alternatives can be considered as two vectors in the real multidimensional real space. The angle between $A_{i}$ and $A_{j}$ in the real space is a proper measure for their conflict. According to Figure 5 if $\theta_{i j}=0$, then $A_{i}$ and $A_{j}$ have no conflicts. When $\theta_{i j} \neq 0$ and $\theta \in(0, \pi / 2)$, conflict is possible. The reason is that, when $\theta_{i j}=0$, gradients of two alternatives will simultaneously be uniform while increasing, therefore, there is no conflict between them. When $\theta_{i j}=0$, that is, when gradients of $A_{i}$ and $A_{j}$ are not coincident, conflict will occur.

Degree of conflict between $A_{i}$ and $A_{j}$ is stated in this way:

$$
\operatorname{COS} \theta_{i j}=\frac{\sum_{k=1}^{m} x_{i k} x_{j k}}{\left(\sum_{k=1}^{m} x_{i k}^{2} \sum_{k=1}^{m} x_{j k}^{2}\right)^{1 / 2}}
$$

$\theta_{i j}$ is the angle between two alternatives and $\left(x_{i 1}, x_{i 2}, \ldots, x_{i n}\right)$ and $\left(x_{j 1}, x_{j 2}, \ldots, x_{j n}\right)$ are gradients of $A_{i}$ and $A_{j}$, respectively.

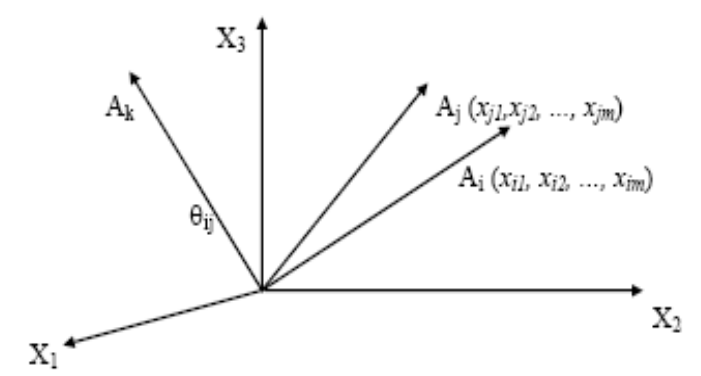

Figure 5. Degree of conflict between alternatives by gradients

According to degree of conflict among the alternatives, degree of similarity between the two alternatives can be calculated. Degree of similarity between $A_{i}$ and $A_{j}$, represented $b S_{i j} y$, measures relative similarity (closeness) of two alternatives and can be calculated in this way:

$$
S_{i j}=\frac{\left(\sum_{k=1}^{m} x_{i k}^{2}\right)^{1 / 2} \cos \theta_{i j}}{\left(\sum_{k=1}^{m} x_{j k}^{2}\right)^{1 / 2}}
$$

$\theta_{i j}$ is the angle between two alternatives $A_{i}$ and $A_{j}$ and present degree of conflict. The larger $S_{i j}$, the higher degree of similarity between alternatives $A_{i}$ and $A_{j}$.

\section{Phases of Similarity-Based Approach}

Structure of the problem is defined and the concepts are stated above. We need take the following steps in order to solve the problem now:

Step 1: determine the decision matrix

$$
X=\left[\begin{array}{cccc}
x_{11} & x_{12} & \ldots & x_{1 m} \\
x_{21} & x_{22} & \ldots & x_{1 m} \\
\vdots & \vdots & \vdots & \vdots \\
x_{n 1} & x_{n 1} & \ldots & x_{n m}
\end{array}\right]
$$

Step 2: determine the weighted vectors of criteria.

$$
W=\left(w_{1}, w_{2}, \ldots, w_{m}\right)
$$

Step 3: normalize the decision matrix using the following formula:

$$
x_{i j}^{\prime}=\frac{x_{i j}}{\sqrt{\sum_{k=1}^{n} x_{i k}^{2}}}
$$


Normalized matrix can be defined as follows:

$$
X^{\prime}=\left[\begin{array}{cccc}
x_{11}^{\prime} & x_{12}^{\prime} & \ldots & x_{1 m}^{\prime} \\
x_{21}^{\prime} & x_{22}^{\prime} & \ldots & x_{1 m}^{\prime} \\
\vdots & \vdots & \vdots & \vdots \\
x_{n 1}^{\prime} & x_{n 1}^{\prime} & \ldots & x_{n m}^{\prime}
\end{array}\right]
$$

Step 4: determine weighted normal matrix; in this step, normalized matrix is multiplied by weighted vector of criteria so that performance of each alternative regarding concerned criterion will be obtained. This matrix is in the following form:

$$
\begin{aligned}
& X^{\prime}=\left[\begin{array}{cccc}
w_{1} x_{11}^{\prime} & w_{2} x_{12}^{\prime} & \ldots & w_{m} x_{1 m}^{\prime} \\
w_{1} x_{21}^{\prime} & w_{2} x_{22}^{\prime} & \ldots & w_{m} x_{1 m}^{\prime} \\
\vdots & \vdots & \vdots & \vdots \\
w_{1} x_{n 1}^{\prime} & w_{2} x_{n 1}^{\prime} & \ldots & w_{m} x_{n m}^{\prime}
\end{array}\right] \\
& =\left[\begin{array}{cccc}
y_{11} & y_{12} & \ldots & y_{1 m} \\
y_{21} & y_{22} & \ldots & y_{1 m} \\
\vdots & \vdots & \vdots & \vdots \\
y_{n 1} & y_{n 1} & \ldots & y_{n m}
\end{array}\right]
\end{aligned}
$$

Step 5: determine positive and negative ideal solution; if each criterion increases or decreases uniformly, positive (or negative) ideal solution includes the best (or the worst) available value of criterion for all alternatives. In this regard, negative and positive ideal solutions are derived from weighted normal matrix as follows:

$$
\begin{aligned}
& A^{+}=\left\{\left(\underset{i}{\left.\left.\max y_{i j}^{\prime} \mid j \in J\right), i=1,2,3, \ldots n\right\}}\right.\right. \\
& =\left\{y_{1}^{+}, y_{2}^{+}, \ldots, y_{m}^{+}\right\} \\
& A^{-}=\left\{\left(\min _{i} y_{i j}^{\prime} \mid j \in J\right), i=1,2,3, \ldots n\right\} \\
& =\left\{y_{1}^{-}, y_{2}^{-}, \ldots, y_{m}^{-}\right\}
\end{aligned}
$$

Step 6: calculate index of conflict among alternatives and positive and negative ideal solutions; degree of conflict between each alternative, $A_{i}$, and positive (negative) ideal solution is estimated in this way:

$$
\begin{gathered}
\operatorname{COS} \theta_{i+}=\frac{\sum_{j=1}^{m} y_{i j}^{\prime} y_{j}^{+}}{\left(\sum_{j=1}^{m} y_{i j}^{\prime 2} \sum_{j=1}^{m} y_{j}^{+^{2}}\right)^{1 / 2}} \\
\operatorname{Cos} \theta_{i-}=\frac{\sum_{j=1}^{m} y_{i j}^{\prime} y_{j}^{-}}{\left(\sum_{j=1}^{m} y_{i j}^{\prime 2} \sum_{j=1}^{m} y_{j}^{-^{2}}\right)^{1 / 2}}
\end{gathered}
$$

Step 7: calculate degree of similarity between each alternative and both positive and negative ideal solution; degree of similarity between each alternative $A_{i}$ and ideal solutions is defined below:

$$
\begin{aligned}
& S_{j}^{+}=\frac{\left(\sum_{k=1}^{m} y_{i k}^{\prime 2}\right)^{1 / 2} \operatorname{Cos} \theta_{i+}}{\left(\sum_{j=1}^{m} y_{j}^{+^{2}}\right)^{1 / 2}} \\
& S_{j}^{-}=\frac{\left(\sum_{k=1}^{m} y_{i k}^{\prime 2}\right)^{1 / 2} \operatorname{CoS} \theta_{i-}}{\left(\sum_{j=1}^{m} y_{j}^{-{ }^{2}}\right)^{1 / 2}}
\end{aligned}
$$


Step 8: calculate general performance index for each alternative against all criteria; according to concepts of degree of similarity of alternative $A_{i}$ relative to ideal solution, a general performance index for each alternative against all criteria is calculated:

$$
P_{i}=\frac{S_{i}^{+}}{S_{i}^{+}+S_{i}^{-}}, \quad i=1,2, \ldots, n
$$

Step 9: sort the criteria in a descending order; the higher index is more preferable (Deng, 2007).

\subsection{Topsis (Technique for Order-Preference by Similarity to Ideal Solution)}

TOPSIS model was proposed by Youn and Hwang in 1981. It is one of compensating methods in MADM. Compensating means that exchange (transaction) among indices is permitted in this model. For instance, weakness of one index is compensated by score of the other index (Asgharpour, 1998).

In this model, distance of an alternative, $\mathrm{A}_{\mathrm{i}}$, from negative ideal solution is considered in addition to its distance from positive one. That is, selected alternative must have the least distance from positive ideal solution while being the most distant from the negative one (Fernandez \& Gomez, 2007).

\subsubsection{Phases of TOPSIS Method}

TOPSIS method evaluates a decision matrix including $m$ alternative and $n$ indices.

Step 1-4: These steps (1 to 4) of the TOPSIS method are similar to the mentioned steps of the previous method, Similarity-Based Approach.

Step 5: determine the ideal and the negative ideal solution.

In this step, we use parameters $\mathrm{A}^{+}$as positive ideal alternative and $\mathrm{A}^{-}$as negative ideal alternative in order to determine the best and the worst solutions. This parameter is obtained in this way:

$$
\begin{aligned}
& A^{+}=\left\{\left(\underset{i}{\max } y_{i j} \mid j \in J\right),\left(\min _{i} y_{i j} \mid\right.\right. \\
& \left.\left.j \in J^{\prime}\right), i=1,2,3, \ldots, m\right\}= \\
& \left\{y_{1}^{+}, y_{2}^{+}, \ldots, y_{j}^{+}, \ldots, y_{n}^{+}\right\} \\
& A^{-}=\left\{\underset{i}{\left(\min _{i j} \mid j \in J\right),\left(\max _{i} y_{i j} \mid\right.}\right. \\
& \left.\left.j \in J^{\prime}\right) i=1,2,3, \ldots, m\right\}= \\
& \left\{y_{1}^{-}, y_{2}^{-}, \ldots, y_{j}^{-}, \ldots, y_{n}^{-}\right\}
\end{aligned}
$$

$j$ s are related to profit index $j \in J=\{j=1,2,3, \ldots, n\}$

Step 6: calculate distances.

In this step, distance of each alternative from superior solution (the most or the least ideal) is calculated according to its type (profit or cost) using Euclidian distance method (n-dimension) as follows:

$$
\begin{aligned}
& d_{i}^{+}=\sqrt{\sum_{j=1}^{n}\left(y_{i j}-y_{j}^{+}\right)^{2}} ; i=1,2, \ldots, m \\
& d_{i}^{-}=\sqrt{\sum_{j=1}^{n}\left(y_{i j}-y_{j}^{-}\right)^{2}} ; i=1,2, \ldots, m
\end{aligned}
$$

Where parameter $d_{i}^{+}$represents the distance of $i$ th alternative from positive ideal and $d_{i}^{-}$represents the distance of $i$ th alternative from negative ideal.

Step 7: calculate relative closeness to the best solution.

In this step, relative closeness of each alternative to the ideal solution is calculated using parameter $C L_{i}^{+}$.

$$
C L_{i}^{+}=\frac{d_{i}^{-}}{d_{i}^{+}+d_{i}^{-}}, \quad 0 \leq C L_{i}^{+} \leq 1, \quad i=1,2, \ldots, m
$$

Step 7: rank the alternatives. 
Resulted $\mathrm{CL}_{i}{ }^{+}$are sorted in descending order so that we can sort and prioritize the alternatives. Therefore, their importance and priority depends on magnitude of their numbers and each alternative which has the largest $C L_{i}^{+}$ has more importance and priority for being selected.

\subsection{Optimizing Stock Portfolio}

The main point when optimizing a portfolio is optimal selection of assets and securities with a given amount of capital in hand (Markowitz, 1952). Although minimizing risk and maximizing return of investment seems easy, many methods have been applied to establish an optimal portfolio in practice. Markowitz stated the modern portfolio theory in a mathematical form. In mean-variance model, mean represent expected return and variance represent risk of portfolio.

In 1952, Markowitz was first that introduce a solution pattern for selecting an optimal set of assets (mean-variance theory). He defined this issue as a quadratic programming aimed at minimizing variance of a set of assets given that expected return equals a constant value. That all investors are risk-averse is the main assumption of this model. This problem has another functional limitation according to which sum of weights for all assets must equal 1. In addition, weight of each asset should be a real non-negative number. Standard form of mean-variance model is here: (Markowitz, 1952)

$$
\begin{gathered}
\min \text { imize } \sum_{i=1}^{N} \sum_{j=1}^{N} w_{i} w_{j} \sigma_{i j} \\
\text { subject to } \sum_{i=1}^{N} w_{i} r_{i}=R \\
\sum_{i=1}^{N} w_{i}=1 \\
0 \leq w_{i} \leq 1, i=1,2, \ldots, n
\end{gathered}
$$

\section{Genetic Algorithm}

Evolutional calculations idea was coined, in 1960, by Rechenberg who studied evolutional research strategies, whose theory was developed by the other researchers afterwards. Primary (basic) principles of genetic algorithm were proposed by Holland and his colleagues in University of Michigan in 1962. They focused on evolution process in natural systems and tried to model it in artificial systems, which should have the same basic abilities as natural systems. These attempts leaded to emergence of genetic algorithm (Holland, 1975).

To use a genetic algorithm, solutions to problem must represent as a genome (or chromosome). Genetic algorithm starts with many individual solutions randomly generated to form an initial population (Mitchel, 1999). Three operations including selection, crossover and, mutation are usually applied on chromosomes so that new generation of the population emerges. This evolution seeks better solutions. These algorithms generally consist of following parts:

\subsection{Fitness Function}

Fitness function is an important part of an evolutionary algorithm and consumes much of the time required for implementing it. This function determines degree of fitness for each solution.

Here, we are going to calculate and draw Markowitz efficient frontier using genetic algorithm. Therefore, fitness function is considered in this way (Fernandez \& Gomez, 2007).

$$
\begin{aligned}
& \min \text { imize } \lambda\left[\sum_{i=1}^{n} \sum_{j=1}^{n} w_{i} w_{j} \sigma_{i j}\right]+ \\
& (1-\lambda)\left[-\sum_{i=1}^{n} w_{i} r_{i}\right] \\
& \text { subject to } \sum_{i=1}^{n} w_{i}=1 \\
& \quad 0 \leq w_{i} \leq 1, i=1,2, \ldots, n
\end{aligned}
$$

In above model, $\lambda$ is a parameter for assigning weights which ranges in a given interval, $[0,1]$. By changing value of $\lambda$, just like changing expected rate of return, it is possible to trace efficient frontier using second order programming. That is, assuming $\lambda=0$, total value of weight coefficient is assigned to return and a maximum 
return stock portfolio will be selected while assuming $\lambda=1$, total value of weight coefficient is assigned to risk and a minimum risk stock portfolio will be selected. Finally, in the interval between 0 and 1, portfolios with an exchange relationship between risk and return are optimized. In the other words, as value of coefficient $\lambda$ increases goal of reducing risk will have more importance and at the same time as value of $(1-\lambda)$ decreases, maximization return weight will be smaller.

Determination of structures, genes and chromosomes: the most important point in the proposed model is to determine type and structure of genes and chromosomes so that each chromosome represents potential and feasible solution. Each chromosome consists of two parts in order to solve the mentioned bounded problem: first part, genes $x_{1}, \ldots, x_{k}$, determines type of stocks to be invested in using stocks numbers (natural numbers). Its length, $\mathrm{K}$, represents the number of shares to be investigate and second part, $\mathrm{m}_{1}, \ldots, \mathrm{m}_{\mathrm{k}}$, whose number of genes is exactly the same as previous part represents weights of the stocks included in the first part. Proposed genes and chromosomes to solve the problem

\begin{tabular}{|l|l|l|l|l|l|l|l|l|l|}
\hline$x_{1}$ & $x_{2}$ & $x_{3}$ & $x_{4}$ & $x_{k}$ & $m_{1}$ & $m_{2}$ & $m_{3}$ & $m_{4}$ & $m_{k}$ \\
\hline
\end{tabular}

Figure 6. Structure of the chromosomes

\subsection{Applying Operators}

Selection operator: tournament selection is the operator used in the proposed mode (Goldberg \& Deb, 1991). It means two parents are selected for each member of the population.

Crossover operator: uniform crossover is used as crossover operator in the proposed model. In this method, two parents give birth to a child. A gene, selected randomly from genes of the parents, is assigned to each child. The proposed model in genetic algorithm can easily employ the above crossover operator on the genes; but in the part of shares numbers, that is the first part of the chromosomes, the requirement of non-repetitive numbers should be tested and in case that, considering non-repetitive requirement, a gene or some genes of children are not filled by parents, a random share which doesn't exist in the child will fill that gene.

Mutation operator: employed chromosomes consist of two parts: share number and share weight in stock portfolio. This operator is applied on genes with a random rate, so a random number, $r$, where $r \in\{1,2,3\}$, is generated for each gene. If $r=1$, value of that gene is multiplied by $1+\mathrm{R}$. Then if $r=2$, then value of that gene is multiplied by 1 -Rand. Finally if $r=0$, value of that gene is not changed $(0<\operatorname{Rand}<1)$.

\subsection{Results of Genetic Algorithm}

We depicted efficient frontier and calculated Sharpe performance ratio to test proposed model. We selected 3 portfolios consisting of 10, 15, 20 top ranked stocks of the two approaches respectively and calculated efficient frontier and Sharpe performance ratio for these three portfolios. Codes of the proposed algorithm were entered and executed in MATLAB software, so that they would be implemented and evaluated. Parameters of the model were determined based on literature review and prior research. Algorithm repeats 800 times until it finishes, number of population is 20 , crossover operator probability is 0.8 , and mutation operator probability is 0.05 . Variable $\mathrm{k}$ represents number of shares that an investor wants to keep in his portfolio. Its value is set to 5,10 and 15 in this study.

As figures show, efficient frontier for all portfolios selected according to Similarity-based approach is higher than that of TOPSIS approach. As It can be seen below; Sharpe ratio was calculated in 10 points using MATLAB software so that performance of the portfolio was evaluated: As above table, proposed model had a higher Sharpe ratio at all points. 


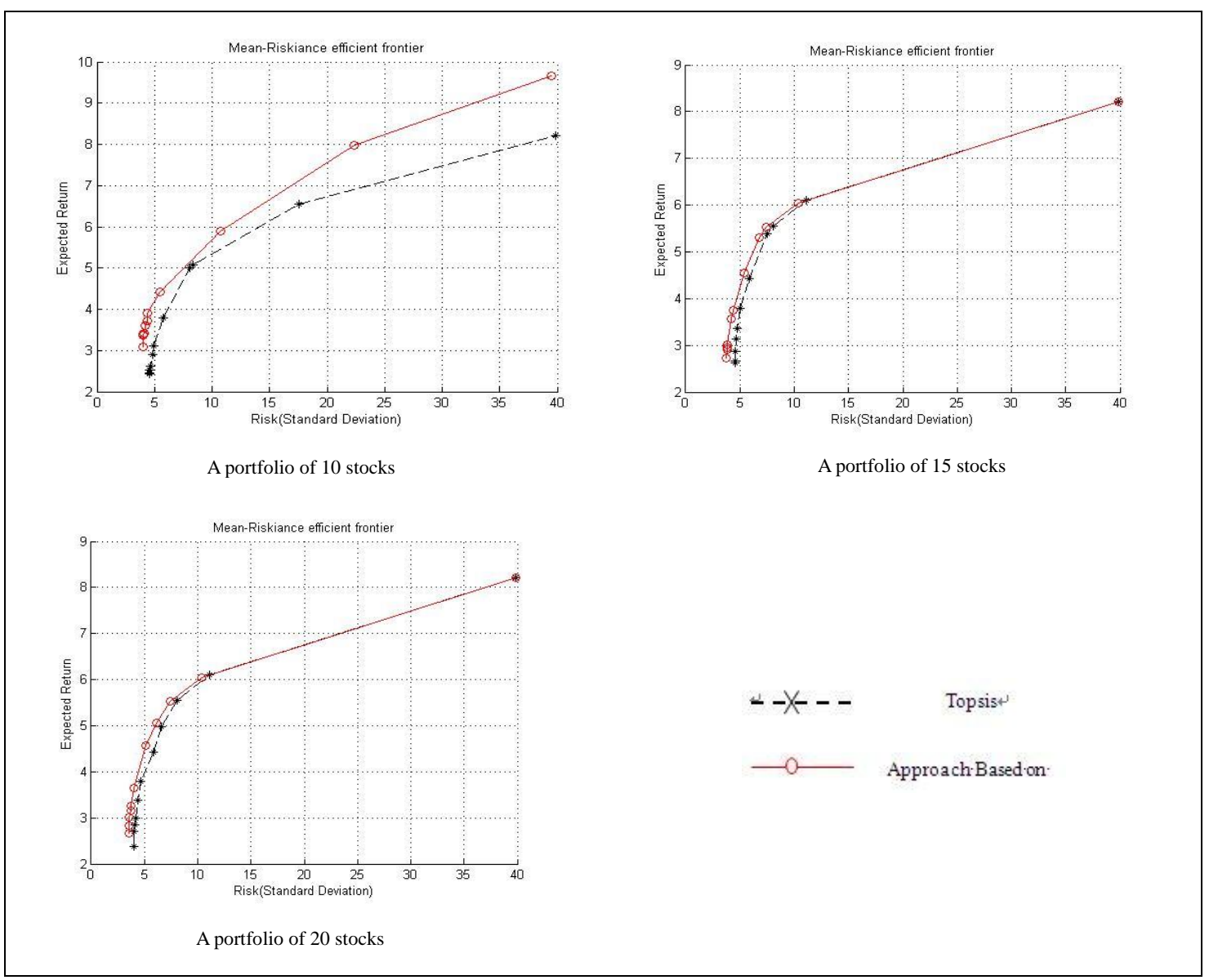

Figure 7. Efficient frontier of selected portfolios

Table 4. Sharp ratios of portfolios

\begin{tabular}{cccccccc}
\hline \multirow{2}{*}{ point } & $\begin{array}{c}\text { Risk } \\
\text { avertion } \\
\text { coefifcient }\end{array}$ & TOPSIS & $\begin{array}{c}\text { Similarity-Based } \\
\text { Approach }\end{array}$ & TOPSIS & $\begin{array}{c}\text { Similarity-Based } \\
\text { Approach }\end{array}$ & TOPSIS & $\begin{array}{c}\text { Similarity-Based } \\
\text { Approach }\end{array}$ \\
\cline { 2 - 7 } & 0.1 & 0.030318 & 0.03106 & 0.044718 & 0.047206 & 0.044719 & 0.047205 \\
2 & 0.2 & 0.04924 & 0.050436 & 0.055805 & 0.060301 & 0.055805 & 0.0603 \\
3 & 0.3 & 0.049894 & 0.06512 & 0.057744 & 0.063198 & 0.061281 & 0.066429 \\
\hline
\end{tabular}

Table 5. Sharp ratios of portfolios

\begin{tabular}{cccccccc}
\hline \multirow{2}{*}{ point } & $\begin{array}{c}\text { Risk } \\
\text { avertion } \\
\text { coefifcient }\end{array}$ & TOPSIS & $\begin{array}{c}\text { Similarity-Based } \\
\text { Approach }\end{array}$ & TOPSIS & $\begin{array}{c}\text { A portfolio of 10 stocks } \\
\text { Approach }\end{array}$ & A portfolio of 15 stocks & \multicolumn{2}{c}{ A portfolio of 20 stocks } \\
\hline 4 & 0.4 & 0.052117 & 0.07056 & 0.060771 & 0.068166 & 0.060771 & $\begin{array}{c}\text { Similarity-Based } \\
\text { Approach }\end{array}$ \\
\hline 5 & 0.5 & 0.049547 & 0.070801 & 0.059971 & 0.069083 & 0.06461 & 0.071756 \\
6 & 0.6 & 0.047055 & 0.07013 & 0.05682 & 0.067587 & 0.061671 & 0.068848 \\
\hline
\end{tabular}

Table 6. Sharp ratios of portfolios

\begin{tabular}{cccccccc}
\hline point & $\begin{array}{c}\text { Risk } \\
\text { avertion } \\
\text { coefifcient }\end{array}$ & \multicolumn{2}{c}{ A portfolio of 10 stocks } & \multicolumn{2}{c}{ A portfolio of 15 stocks } & \multicolumn{2}{c}{ A portfolio of 20 stocks } \\
\cline { 2 - 7 } & 0.7 & 0.044408 & $\begin{array}{c}\text { Similarity-Based } \\
\text { Approach }\end{array}$ & TOPSIS & $\begin{array}{c}\text { Similarity-Based } \\
\text { Approach }\end{array}$ & TOPSIS & $\begin{array}{c}\text { Similarity-Based } \\
\text { Approach }\end{array}$ \\
\hline 7 & 0.06671 & 0.054411 & 0.062289 & 0.057489 & 0.066693 \\
8 & 0.8 & 0.043026 & 0.06636 & 0.049383 & 0.060327 & 0.052553 & 0.066617 \\
\hline 9 & 0.9 & 0.041778 & 0.06764 & 0.04425 & 0.062248 & 0.054021 & 0.063171 \\
10 & 1 & 0.041367 & 0.05589 & 0.045664 & 0.056563 & 0.046206 & 0.05924 \\
\hline
\end{tabular}




\section{Conclusion}

Many investors strive to establish an optimal portfolio in order to succeed in financial markets. Various models and methods have been proposed to establish a portfolio, most of which are not useful for public due to their difficult mathematical calculations. In this study, we ranked superior stocks using decision making models. The most important advantage of using decision making algorithms in investment decisions is the ability to incorporate personal preferences in these models. Therefore, we calculated weight of each criterion according to experts' opinions using fuzzy analysis network process. Incorporating experts' opinions caused criteria relating to profitability and growth groups gain more relative importance than criteria of other groups, of course this could be predicted. Additionally, two criteria of return on assets and return on equity can determine management's ability to use resources optimally. But, according to experts' opinions, criteria regarding growth are of special importance. It appears that ability to continue profitable processes which growth criteria measure efficiently, is a reason of such an attention. Finally, criteria of market group and risk group have subsequent orders.

Consequently, those 80 shares are ranked and they studied by similarity-based approach proposed in 2007 and one more time using TOPSIS method. We depicted the efficient frontier for portfolios consisting of 10,15 and 20 top ranked shares of these two methods using genetic algorithm, in order to evaluate performance of proposed approach. It is seen that efficient frontier of proposed approach is higher than that of TOPSIS method. Furthuremore, Sharpe performance ratios of two approaches were calculated in 10 points by which, efficient frontier was depicted, and again, it is calculated that proposed approach provid higher numbers.

\section{References}

Amiri, M., Shariatpanahi, M., \& Banakar, M. H. (2010). Portfolio Selection With the Use of MCDM. Quarterly Journal of Securities Exchange.

Asgharpour, M. J. (1998). MCDM. Tehran, Iran, Persian.

Brickley, J. (1983). Shareholder Wealth, Information Signaling and the Specially Designated Dividend: An

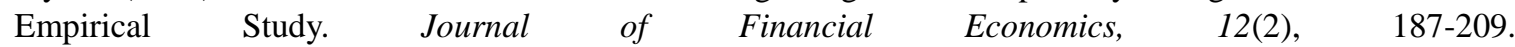
http://dx.doi.org/10.1016/0304-405X(83)90035-1

Brigham, E. F., \& Ehrhardt, M. C. (n.d.). Financial Management: Theory and Practice (11th ed.). Thomson South Western.

Chang, D. Y. (1992). Extent analysis and synthetic decision, optimization techniques and applications (p. 352). Singapore: World Scientific.

Chang, D. Y. (1996). Applications of the extent analysis method on fuzzy AHP. European Journal of Operational Research, 95, 649-655. http://dx.doi.org/10.1016/0377-2217(95)00300-2

Deng, H. (2007). A Similarity-Based Approach to Ranking Multicriteria Alternatives (pp. 253-262). Springer. http://dx.doi.org/10.1007/978-3-540-74205-0_28

Edirisinghe, N. C. P., \& Zhang, X. (2008). Portfolio Selection Under DEA-Based Relative Financial Strength Indicators: Case of Us Industries. Journal of the Operational Research Society, 59, 842-856. http://dx.doi.org/10.1057/palgrave.jors.2602442

Fama, E. F., \& French, K. R. (1992). The Cross-Section of Expected Stock Returns. Journal of Finance, 47(2), 427-466. http://dx.doi.org/10.1111/j.1540-6261.1992.tb04398.x

Fernandez, A., \& Gomez, S. (2007). Portfolio Selection Using Neural Networks. Computers \& Operations Research, 34, 1177-1191. http://dx.doi.org/10.1016/j.cor.2005.06.017

Gholizadeh, M. H. (2004). Designing a Model to Rank Firms Listed in Tehran Stock Exchange Using Data Envelopment Analysis (Case: Food and Beverage Industry). PhD. Thesis, Tehran university, Tehran, Iran. http://dx.doi.org/10.1016/b978-0-08-050684-5.50008-2

Goldberg, D. E., \& Deb, K. (1991). A Comparative Analysis of Selection Schemes Used in Genetic Algorithms. Morgan Kaufmann.

Higgins, R. C. (1977). How much growth can a firm afford? Financial Management Fall, 7-16. http://dx.doi.org/10.2307/3665251

Holland, J. H. (1975). Adaptation in Natural and Artificial Systems. University of Michigan Press. 
Kahraman, C., Ruan, D., \& Tolga, E. (2002). Capital Budgeting Techniques Using Discounted Fuzzy Versus $\begin{array}{lllll}\text { Probabilistic Cash } & \text { Flows. Information } & \text { Sciences, } & \text { 142, } & \text { 57-76. }\end{array}$ http://dx.doi.org/10.1016/S0020-0255(02)00157-3

Kiris, S., \& Ustun, O. (2010). Fuzzy MCDM approach of stocks evaluation and portfolio selection. The Journal of the Operational Research Society.

Lee, A. H. I., Chen, W. C., \& Chang, C. J. (2008). A Fuzzy AHP and BSC Approach for Evaluating Performance of IT Department in the Manufacturing Industry in Taiwan. Expert Systems with Application, 34, 96-107.

Lee, W. S., Haung, A. Y., Chang, Y. Y., \& Cheng, C. M. (2011). Analysis of Decision Making Factors for Equity Investment by Dematel and Analytic Network Process. Expert Systems with Applications, 38(7).

Lee, W. S., Tzeng, G. H., Guan, J. L., Chien, K. T., \& Huang, J. M. (2008). Combined Mcdm Techniques for Exploring Stock Selection Based on Gordon Model. Expert Systems with Applications, 36(3), 6421-6430.

Markowitz, H. M. (1952). Portfolio Selection. Journal of Finance, 77-91.

Meziani, S. (2003). Aaaessing the Effect of Investment Barriers on International Capital Flow Using an Expert-system. The Multinational Business Review, 11.

Mitchel, M. (1999). An Introduction to Genetic Algorithms. MIT Press.

Raei, R., \& Pooyan Far, A. (2004). Advanced Investment Management. SAMT, Tehran, Persian.

Reilly, F. K, \& Brown, K. C. (2003). Investment Analysis and Portfolio Selection (6th ed.).

Ross, S., Westerfield, R., Jordan, B., \& Roberts, G. (2002). Fundamental of Corporate Finance (4th ed.). Mcgraw-Hill.

Saaty, T. L. (1996). Decision Making with Dependence and Feedback: The Analytic Network Process. RWS Publications, Pittsburgh, PA.

Saremi, M., Safari, H., Fathi, H., \& Hoseini, F. (2006). Proposing A Model To Rank Informatics Companies. Journal of Trade Studies, 40(40), 127-154.

Tiryaki, F., \& Ahlatcioglu, B. (2009). Fuzzy Portfolio Selection Using Fuzzy Analytic Hierarchy Process (p. 179). Information Sciences.

Zadeh, L. A. (1965). Fuzzy sets. Information and Control, 8(3), 338-353.

\section{Copyrights}

Copyright for this article is retained by the author(s), with first publication rights granted to the journal.

This is an open-access article distributed under the terms and conditions of the Creative Commons Attribution license (http://creativecommons.org/licenses/by/3.0/). 